\title{
Impact of endoscopic resection on the choice of surgical procedure in patients with additional laparoscopic gastrectomy
}

\author{
Junya Aoyama ${ }^{1} \cdot$ Shinichi Sakuramoto $^{1}$-Yutaka Miyawaki ${ }^{1} \cdot$ Misato Ito $^{1} \cdot$ Sunao Ito ${ }^{1} \cdot$ Kenji Watanabe $^{1}$. \\ Shuichiro Oya ${ }^{1} \cdot$ Naoto Fujiwara ${ }^{1} \cdot$ Hirofumi Sugita ${ }^{1} \cdot$ Kouichi Nonaka $^{2} \cdot$ Hiroshi Sato $^{1} \cdot$ Masanori Yasuda $^{3}$. \\ Shigeki Yamaguchi ${ }^{1}$
}

Received: 26 December 2019 / Accepted: 4 March 2020 / Published online: 16 March 2020

(c) The International Gastric Cancer Association and The Japanese Gastric Cancer Association 2020

\begin{abstract}
Background Additional surgery is recommended for patients with noncurative resection after endoscopic submucosal dissection (ESD) for early gastric cancer. Additional resection requires the excision of an area larger than that of the resected mucosa in ESD, which is larger than the lesion, with convergence of the gastric mucosa due to scarring. Thus, the selection of the surgical procedure for lesion removal in specific areas can be affected by ESD. This study therefore aimed to evaluate the impact of ESD on the selection of additional gastrectomy in patients with early gastric cancer in the boundary area between the upper third and middle third of the stomach (UM boundary region).

Methods Between January 2013 and June 2018, laparoscopic gastrectomy was performed in 89 patients with cT1N0M0 gastric cancer located only in the UM boundary region. The patients' backgrounds and surgical and pathological results were retrospectively investigated. The predictive factors for performing laparoscopic distal gastrectomy (LDG) were evaluated by multivariate analysis.

Results Among 89 patients, 23 patients underwent ESD before surgery. LDG was significantly less often performed in the ESD-surgery group than in the surgery-only group (34.8\% vs. $72.7 \% ; p=0.003)$. Preoperative ESD was an independent negative predictor of LDG (odds ratio $=0.266 ; p=0.025$ ).

Conclusions Preoperative ESD has an impact on the selection of the type of additional gastrectomy, including reducing the conduct of LDG for early gastric cancer in the UM boundary region.
\end{abstract}

Keywords Early gastric cancer $\cdot$ Endoscopic submucosal dissection $\cdot$ Gastrectomy $\cdot$ Laparoscopy

\section{Introduction}

Recent advances in diagnostic technology have facilitated the early detection of gastric cancer, especially in Japan and Korea [1-3]. Patients with early gastric cancer (EGC) with a low risk of lymph node metastasis are generally treated by endoscopic submucosal dissection (ESD). ESD for EGC

Junya Aoyama

junya.aoyama7@gmail.com

1 Department of Gastroenterological Surgery, Saitama Medical University International Medical Center, Hidaka 350-1298, Japan

2 Department of Gastroenterology, Saitama Medical University International Medical Center, Hidaka 350-1298, Japan

3 Department of Pathology, Saitama Medical University International Medical Center, Hidaka 350-1298, Japan is used for treating absolute indications such as intramucosal differentiated-type adenocarcinoma and $2 \mathrm{~cm}$ or less in tumor size without ulceration [4] and has been expanded to cover other conditions as an investigational treatment [4-6]. In clinical practice, diagnostic ESD may be performed as a relative indication in patients at high risk for adverse surgical outcomes such as the elderly, even if submucosal invasion is clinically suspected. Patients who do not fulfill the pathological criteria for curative resection are considered for noncurative resection because of the potential risk of lymph node metastasis or a local residual tumor [4]. Therefore, additional surgical resection with lymph node dissection is recommended for these patients [4].

Acceptance has been growing for the use of laparoscopic gastrectomy as a standard procedure for the treatment of EGC due to its good safety profile and advantages over conventional open gastrectomy [7-10]. ESD causes 
the appearance of an artificial gastric ulcer, which induces local inflammation, edema, fibrosis, and intraabdominal adhesions. These ESD-induced effects might increase the level of technical difficulties seen during additional laparoscopic gastrectomy after ESD [11]. Previous studies have clarified the oncological safety profile and technical feasibility of performing additional laparoscopic gastrectomy $[12,13]$.

Generally, the surgical procedure is determined based on the location of the lesion. However, gastric cancer located in the upper gastric body (defined as the upper third of the region from the cardia to the angle) is resected with both distal gastrectomy (DG) and proximal gastrectomy [14]. The preservation of the fundus - that is, whether laparoscopic distal gastrectomy (LDG) can be performed-is one of the important points capable of affecting the patient's quality of life. This is because LDG has both surgical and nutritional benefits over laparoscopic proximal gastrectomy (LPG) or laparoscopic total gastrectomy (LTG) according to several studies [15, 16]. Overall, LDG is the most common type of laparoscopic gastrectomy, with a significant level of evidence accumulated supporting its use [17-19]. Especially given that LPG and LTG were more recently established [20], there are still some problems that must be overcome in terms of technical difficulties, standard procedures for reconstruction, and postoperative complications such as reflux esophagitis and anastomotic stenosis.

The portion to be excised during additional gastrectomy is larger than the original lesion. This is because the mucosa resected during ESD is larger than the lesion and there is contraction of the tissues at the site of resection during healing of the ESD ulcer. In contrast, the distance from the esophagogastric junction to the proximal margin of the lesion must be secured for performing LDG to ensure a passageway for meals and to avoid cutting into the lower esophageal sphincter, taking into account the width of approximately $1 \mathrm{~cm}$ of the device used to cut the stomach. According to previous studies, the proximal distance from the esophagogastric junction should be at least $2 \mathrm{~cm}$ for performing DG [21, 22]. In fact, Kawata et al. reported three cases in which DG as the estimated gastric resection had to be altered to total gastrectomy because of the contraction of the ESD ulcer [22]. Thus, we hypothesized that for lesions located near the expected cutline for LDG procedure, performing ESD can make it difficult to resect the lesion via LDG, thereby resulting in an increase in the frequency of LPG or LTG.

In this study, we considered the area potentially affected by ESD and any subsequent scarring as the boundary area between the upper third and middle third of the stomach (UM boundary region). Consequently, study participants were limited to those with lesions in the UM boundary region. We evaluated the effects of ESD on the selection of an additional gastrectomy procedure among patients with EGC in the UM boundary region.

\section{Patients and methods}

\section{Patients}

We retrospectively reviewed the data of patients who had undergone gastrectomy for cT1N0M0 cStage I gastric cancer at Saitama Medical University International Medical Center, Saitama, Japan, between January 2013 and June 2018. Among the 487 consecutive patients identified, 426 patients who underwent R0 laparoscopic gastrectomy for single EGC were included after the exclusion of those with remnant gastric cancer, multiple lesions, open surgery, and $\mathrm{R} 1$ resection. Subsequently, after excluding patients with tumors that extended outside the distal one-half of the upper third of the stomach and the proximal one-half of the middle third of the stomach, we finally analyzed 89 patients who underwent laparoscopic gastrectomy for cT1N0M0 cStage I gastric cancer located only in the UM boundary region (Fig. 1). We defined the distal one-half of the upper third of the stomach and the proximal one-half of the middle third of the stomach collectively as the UM boundary region. The clinical staging and pathological examination of all tumors were performed according to the Japanese Classification of Gastric Cancer [4] as proposed by the Japanese Gastric Cancer Association (JGCA). An upper gastrointestinal multidisciplinary team comprising senior staff reviewed the endoscopic findings, computed tomography, and other pretreatment examination findings and selected the appropriate treatment strategies, including surgical and endoscopic resection, based on the guidelines of the JGCA [4]. In surgical resection cases, the tumor location was determined via endoscopy and gastrointestinal series. The proximal margins of the lesion or the ESD scar were marked using clips during endoscopy. Subsequently, an upper gastrointestinal series was performed before surgery in all cases. This study was conducted after obtaining approval from the institutional review board of Saitama Medical University.

\section{Criteria for the noncurative resection of ESD}

A diagnosis of noncurative resection of ESD was made when the pathological findings did not meet the criteria for curative resection as defined in the JGCA guidelines [4]. In other words, patients were diagnosed as having noncurative resection when at least one of the following conditions was met: (1) a differentiated tumor with a size of more than $30 \mathrm{~mm}$ that satisfied at least one of the conditions of $\mathrm{sm} 1$ invasion ( $<500 \mu \mathrm{m}$ ) or ulceration; (2) an undifferentiated tumor that satisfies one of the conditions of submucosal invasion, size 
Fig. 1 Flowchart of patient enrollment. ESD endoscopic submucosal dissection

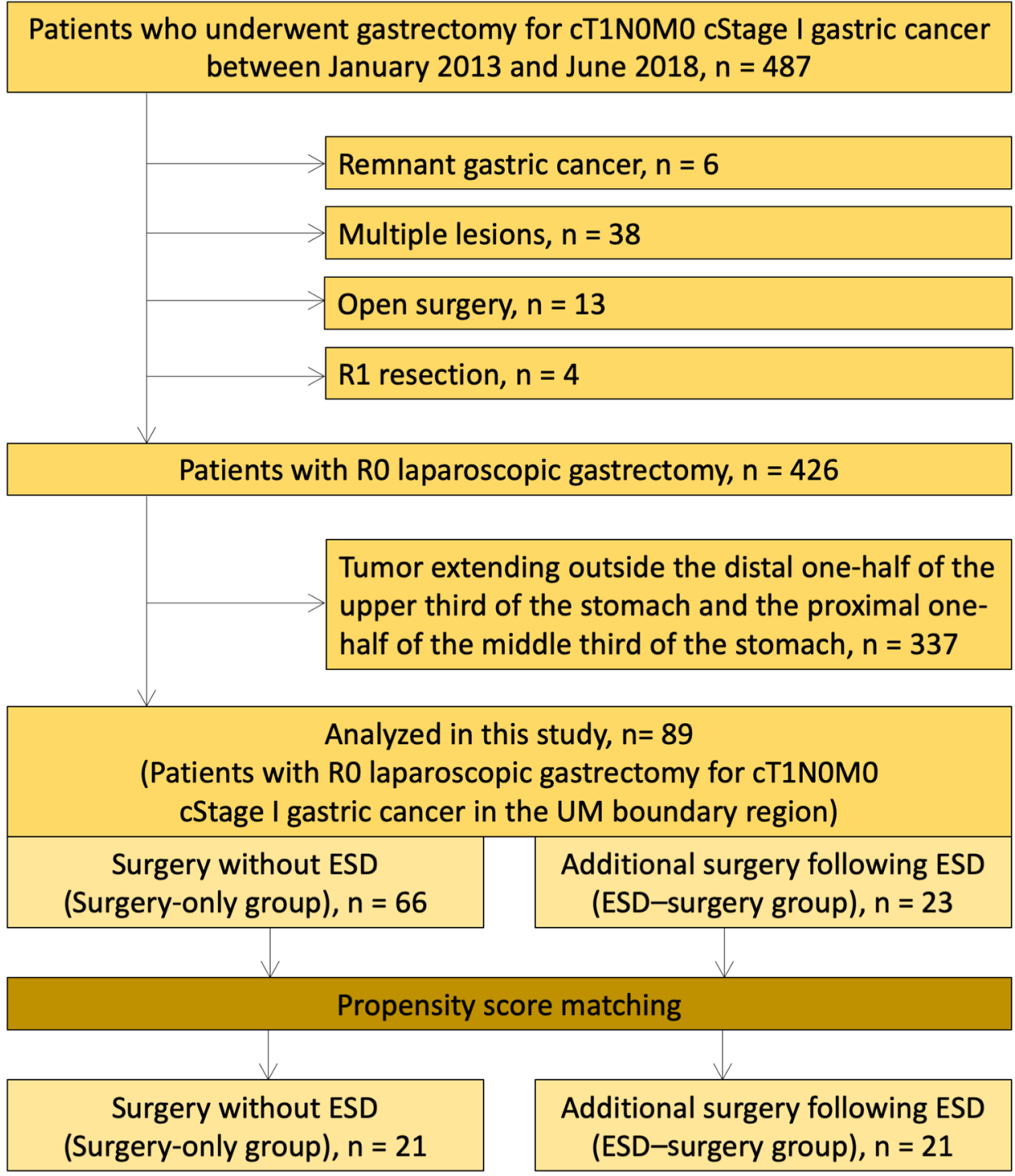

of greater than $20 \mathrm{~mm}$, or ulceration; (3) the presence of lymphatic invasion; (4) the presence of vascular invasion; (5) $\operatorname{sm} 2$ or deeper invasion $(\geq 500 \mu \mathrm{m})$; (6) positive horizontal margin or horizontal margin that could not be assessed; and (7) positive vertical margin or vertical margin that could not be assessed.

\section{Surgical procedure}

At our institution, LDG is the primary choice for the treatment of EGC in the UM boundary region. An upper gastrointestinal multidisciplinary team reviewed all preoperative findings and finally determined whether LDG can be performed based on the virtual cutting line of the stomach, which was determined using proximal marking clips. LPG or LTG was considered if LDG was deemed to be not feasible.

In LDG, a Billroth I reconstruction operation was essentially performed. If the Billroth I procedure was considered difficult to complete based on intraoperative findings including intraoperative endoscopy, then the Roux-en-Y procedure was performed. During LPG, an esophagogastric anastomosis or double-tract reconstruction was performed. During LTG, Roux-en-Y reconstruction via an antecolic route was completed. Finally, in any type of gastrectomy, D1+lymphadenectomy was done.

\section{Propensity score matching}

A propensity score matching analysis was performed to align background factors between study participants who underwent additional gastrectomy after noncurative resection of ESD, labeled as the ESD-surgery group, and those who underwent gastrectomy without ESD, labeled as the surgery-only group. Propensity scores were estimated using a multivariable logistic regression model according to age, sex, preoperative body mass index (BMI), and American 
Society of Anesthesiologists physical status (ASA-PS). Oneto-one matching without replacement was performed using a 0.1 caliper width and the resulting matched pairs were used in subsequent analyses.

\section{Statistical analysis}

Differences in the qualitative data between the two groups were evaluated using the Chi squared test or Fisher's exact test and quantitative data were compared using the Student's $t$ test. A multivariate logistic regression analysis was used to calculate odds ratios (ORs) and their $95 \%$ confidence intervals (CIs) for identifying factors that could influence the decision-making about the type of gastrectomy. A $p$ value of less than 0.05 was considered to be statistically significant. The Statistical Package for the Social Sciences version 25 software program (IBM Corp., Armonk, NY, USA) was used to perform the statistical analyses.

\section{Results}

The clinical characteristics of the patients are summarized in Table 1. Of the 89 included patients, 23 underwent ESD before surgery. The patients in the ESD-surgery group tended to be significantly older, male, and have higher BMI values in comparison with those in the surgery-only group. In addition, the lesions were more likely to be distributed in the lesser curvature in the surgery-only group and in the greater curvature in the ESD-surgery group.

As shown in Table 2, LDG was significantly less often performed in the ESD-surgery group than in the surgeryonly group $(34.8 \%$ vs. $72.7 \%$; $p=0.003)$, while LPG was the most frequently performed operation in the ESD-surgery group $(52.2 \%)$. There was no difference in the operation time, amount of blood loss, or frequency of postoperative complications between the groups, although the length of hospital stay was longer in the ESD-surgery group than in the surgery-only group ( 9 days vs. 8 days; $p=0.041$ ).

The pathological characteristics of the patients are shown in Table 3. The proportion of cases of the differentiated dominant type was significantly higher in the ESDsurgery group than that in the surgery-only group. Further, the depth of tumor invasion included only $\mathrm{pT} 1 \mathrm{~b}$ or $\mathrm{T} 2 \mathrm{in}$ the ESD-surgery group, whereas it included pT1a and T3 as well in the surgery-only group, resulting in a significant difference in the distribution of tumor depth between the two groups. There was no significant difference in the frequency of lymph node metastasis, lymphatic invasion, and venous invasion between the two groups. In addition, the median length of the proximal margin of the tumors resected via LDG was $16 \mathrm{~mm}$. Furthermore, the median proximal margin length of the tumors resected via LPG or LTG was $30 \mathrm{~mm}$.

The median time interval between ESD and subsequent surgery in the ESD-surgery group was 12 weeks. Patients $(n=23)$ in the ESD-surgery group were divided into two

Table 1 Characteristics of the patients before and after propensity score matching

\begin{tabular}{|c|c|c|c|c|c|c|}
\hline & \multicolumn{3}{|l|}{ All patients $(n=89)$} & \multicolumn{3}{|c|}{ Matched patients $(n=42)$} \\
\hline & $\begin{array}{l}\text { Surgery-only group } \\
(n=66)\end{array}$ & $\begin{array}{l}\text { ESD-surgery group } \\
(n=23)\end{array}$ & $p$ value & $\begin{array}{l}\text { Surgery-only group } \\
(n=21)\end{array}$ & $\begin{array}{l}\text { ESD-surgery group } \\
(n=21)\end{array}$ & $p$ value \\
\hline Age (years), mean $\pm S D$ & $64.3 \pm 10.9$ & $70.6 \pm 10.1$ & $0.017^{*}$ & $70.0 \pm 8.2$ & $69.9 \pm 10.3$ & 0.961 \\
\hline Sex: $n(\%)$ & & & $0.003 *$ & & & \\
\hline Male & 38 & 21 & & 19 & 19 & 1.000 \\
\hline Female & 28 & 2 & & 2 & 2 & \\
\hline BMI $\left(\mathrm{kg} / \mathrm{m}^{2}\right)$, mean $\pm \mathrm{SD}$ & $22.6 \pm 3.1$ & $24.3 \pm 1.9$ & $0.012 *$ & $24.0 \pm 2.7$ & $24.1 \pm 1.7$ & 0.967 \\
\hline ASA-PS: $n(\%)$ & & & 0.351 & & & 1.000 \\
\hline 1 & 27 & 6 & & 6 & 6 & \\
\hline 2 & 38 & 17 & & 15 & 15 & \\
\hline 3 & 1 & 0 & & 0 & 0 & \\
\hline Circumference: $n(\%)$ & & & $0.014 *$ & & & $0.018^{*}$ \\
\hline Anterior wall & 7 & 6 & & 1 & 6 & \\
\hline Posterior wall & 22 & 3 & & 7 & 3 & \\
\hline Greater curvature & 11 & 9 & & 3 & 8 & \\
\hline Lesser curvature & 26 & 5 & & 10 & 4 & \\
\hline Tumor size $(\mathrm{mm})$, mean $\pm \mathrm{SD}$ & $28.1 \pm 13.1$ & $27.8 \pm 14.8$ & 0.940 & $31.2 \pm 13.2$ & $27.1 \pm 14.6$ & 0.351 \\
\hline
\end{tabular}

$E S D$ endoscopic submucosal dissection, $S D$ standard deviation, BMI body mass index, ASA-PS American Society of Anesthesiologist physical status

$* p<0.05$ 
Table 2 Operative characteristics and perioperative outcomes of the patients before and after propensity score matching

\begin{tabular}{|c|c|c|c|c|c|c|}
\hline & \multicolumn{3}{|c|}{ All patients $(n=89)$} & \multicolumn{3}{|c|}{ Matched patients $(n=42)$} \\
\hline & $\begin{array}{l}\text { Surgery-only } \\
\text { group }(n=66)\end{array}$ & $\begin{array}{l}\text { ESD-surgery } \\
\text { group }(n=23)\end{array}$ & $p$ value & $\begin{array}{l}\text { Surgery-only } \\
\text { group }(n=21)\end{array}$ & $\begin{array}{l}\text { ESD-surgery } \\
\text { group }(n=21)\end{array}$ & $p$ value \\
\hline Type of gastrectomy, $n(\%)$ & & & $0.003 *$ & & & $0.002 *$ \\
\hline Distal gastrectomy & 48 & 8 & & 17 & 6 & \\
\hline Total gastrectomy & 6 & 3 & & 2 & 3 & \\
\hline Proximal gastrectomy & 12 & 12 & & 2 & 12 & \\
\hline Operation time (min), median (range) & $254(157-421)$ & $250(187-389)$ & 0.847 & $275(194-368)$ & $243(187-350)$ & 0.091 \\
\hline Blood loss (mL), median (range) & $30(0-200)$ & $12(0-130)$ & 0.803 & $37(0-200)$ & $12(0-130)$ & 0.223 \\
\hline Postoperative complications C-D grade $\geq \mathrm{II}, n(\%)$ & 4 & 3 & 0.256 & 2 & 2 & 1.000 \\
\hline Postoperative hospital stay (days), median (range) & $8(6-24)$ & $9(7-31)$ & $0.041 *$ & $8(6-17)$ & $9(7-31)$ & 0.065 \\
\hline
\end{tabular}

$E S D$ endoscopic submucosal dissection, $S D$ standard deviation, $C-D$ Clavien-Dindo classification ${ }^{*} p<0.05$

Table 3 Pathological characteristics of the patients before and after propensity score matching

\begin{tabular}{|c|c|c|c|c|c|c|}
\hline & \multicolumn{3}{|c|}{ All patients $(n=89)$} & \multicolumn{3}{|c|}{ Matched patients $(n=42)$} \\
\hline & $\begin{array}{l}\text { Surgery-only } \\
\text { group }(n=66)\end{array}$ & $\begin{array}{l}\text { ESD-surgery } \\
\text { group }(n=23)\end{array}$ & $p$ value & $\begin{array}{l}\text { Surgery-only } \\
\text { group }(n=21)\end{array}$ & $\begin{array}{l}\text { ESD-surgery } \\
\text { group }(n=21)\end{array}$ & $p$ value \\
\hline $\begin{array}{l}\text { Dominant histologi- } \\
\text { cal type, } n(\%)\end{array}$ & & & $<0.001 *$ & & & $0.004 *$ \\
\hline Differentiated & 26 & 22 & & 12 & 20 & \\
\hline Undifferentiated & 40 & 1 & & 9 & 1 & \\
\hline $\mathrm{pT}, n(\%)$ & & & $0.001 *$ & & & $0.006^{*}$ \\
\hline T1a & 27 & 0 & & 8 & 0 & \\
\hline $\mathrm{T} 1 \mathrm{~b}$ & 29 & 21 & & 12 & 19 & \\
\hline $\mathrm{T} 2$ & 8 & 2 & & 0 & 2 & \\
\hline $\mathrm{T} 3$ & 2 & 0 & & 1 & 0 & \\
\hline $\mathrm{pN}, n(\%)$ & & & 0.581 & & & 0.303 \\
\hline No & 58 & 20 & & 20 & 18 & \\
\hline N1 & 8 & 3 & & 1 & 3 & \\
\hline pStage, $n(\%)$ & & & 0.222 & & & 0.835 \\
\hline IA & 50 & 20 & & 19 & 18 & \\
\hline IB & 13 & 1 & & 1 & 1 & \\
\hline IIA & 2 & 2 & & 1 & 2 & \\
\hline IIB & 1 & 0 & & 0 & 0 & \\
\hline Lymphatic invasion & & & 0.554 & & & 0.500 \\
\hline Negative & 56 & 20 & & 18 & 19 & \\
\hline Positive & 10 & 3 & & 3 & 2 & \\
\hline Venous invasion & & & 0.418 & & & 0.348 \\
\hline Negative & 54 & 20 & & 16 & 18 & \\
\hline Positive & 12 & 3 & & 5 & 3 & \\
\hline
\end{tabular}

$E S D$ endoscopic submucosal dissection, $S D$ standard deviation

$* p<0.05$

groups based on the time interval between ESD and subsequent surgery, with a cutoff of 12 weeks. Surgical procedure and the ratio of the length of the ESD scar to that of the resected mucosa were compared between the two groups (Table 4). The results showed no significant difference in this respect. The mean diameter of the resected mucosa in patients who underwent ESD was $48.3 \mathrm{~mm}$, and the mean tumor size in the ESD-surgery group was $27.8 \mathrm{~mm}$. Of note, the size of the resected mucosa in patients who underwent ESD was significantly larger than the tumor size in 
Table 4 Relationship between surgical procedure and duration after ESD

\begin{tabular}{|c|c|c|c|c|}
\hline & \multirow{2}{*}{$\begin{array}{l}\text { ESD-surgery group } \\
(n=23)\end{array}$} & \multicolumn{2}{|c|}{ The duration between ESD and subsequent surgery } & \multirow[t]{2}{*}{$p$ value } \\
\hline & & $\leq 12$ weeks $(n=12)$ & $>12$ weeks $(n=11)$ & \\
\hline Tumor size $(\mathrm{mm})$, mean $\pm \mathrm{SD}$ & $27.8 \pm 14.8$ & $28.4 \pm 16.5$ & $27.2 \pm 13.5$ & 0.847 \\
\hline Resected mucosal size at ESD $(\mathrm{mm})$, mean \pm SD & $48.3 \pm 21.6$ & $49.4 \pm 22.2$ & $47.0 \pm 12.7$ & 0.590 \\
\hline ESD scar in surgical specimen $(\mathrm{mm})$, mean $\pm \mathrm{SD}$ & $21.6 \pm 9.2$ & $22.6 \pm 9.8$ & $20.5 \pm 8.7$ & 0.750 \\
\hline The scar/resected mucosal size ratio, mean $\pm \mathrm{SD}$ & $0.49 \pm 0.24$ & $0.52 \pm 0.26$ & $0.45 \pm 0.22$ & 0.476 \\
\hline Type of gastrectomy, $n(\%)$ & & & & 0.311 \\
\hline Distal gastrectomy & 8 & 4 & 4 & \\
\hline Total gastrectomy & 3 & 3 & 0 & \\
\hline Proximal gastrectomy & 12 & 5 & 7 & \\
\hline
\end{tabular}

$E S D$ endoscopic submucosal dissection, $S D$ standard deviation

$* p<0.05$

Table 5 Noncurative factors in the ESD-surgery group

\begin{tabular}{lrr}
\hline Factors for noncurative resection (with overlap) & $n$ & $\%$ \\
\hline (1) Differentiated tumor with size $>30 \mathrm{~mm}$ & & \\
Sm1 invasion $(<500 \mu \mathrm{m})$ & 2 & $(8.7)$ \\
Ulceration & & $(0.0)$ \\
(2) Undifferentiated tumor & 1 & $(4.3)$ \\
Submucosal invasion & 0 & $(0.0)$ \\
Size $>20 \mathrm{~mm}$ & 0 & $(0.0)$ \\
Ulceration & 8 & $(34.8)$ \\
(3) Presence of lymphatic invasion & 8 & $(34.8)$ \\
(4) Presence of vascular invasion & 20 & $(87.0)$ \\
(5) Sm2 or deeper invasion $(\geq 500 \mu \mathrm{m})$ & 0 & $(0.0)$ \\
(6) Horizontal margin was positive or could not be & & \\
assessed & 7 & $(30.4)$ \\
(7) Vertical margin was positive or could not be & & \\
$\quad$ assessed & &
\end{tabular}

the surgery-only group $(p<0.001)$. However, no significant difference was observed in terms of tumor size between the surgery-only and ESD-surgery groups. In addition, the mean size of the ESD scar was $21.6 \mathrm{~mm}$, which was less than onehalf of the diameter of the excised mucosa.

The pathological factors influencing the diagnoses of noncurative resection among 23 patients in the ESD-surgery group are shown in Table 5 . The most frequent cause of additional laparoscopic gastrectomy after ESD was sm2 invasion (87.0\%). Lymphatic invasion, venous invasion, and positive vertical margin were recognized in $34.8 \%, 34.8 \%$, and $30.4 \%$ of the patients, respectively.

As indicated, propensity score matching was performed to create comparable groups. The analysis of 21 matched patient pairs showed almost equal distributions of age, sex, BMI, and ASA-PS between the study populations. Even after matching, the frequency of performing LDG was significantly less in the ESD-surgery group than in the surgery-only group ( $28.6 \%$ vs. $81.0 \% ; p=0.002$; Table 2$)$. Regarding dominant histological type, pT stage, and circumference of the tumor, there were significant differences as before matching.

As part of this study, patients were divided into two groups, LDG and non-LDG, to detect factors related to the decision about the type of gastrectomy. Univariate and multivariate analyses were performed involving the LDG and non-LDG groups (Table 6). A univariate analysis verified that the choice of LDG was associated with the dominant histological type $(p=0.022)$ and preoperative ESD $(p=0.001)$. In addition, a multivariate analysis also revealed preoperative ESD (OR 0.266, 95\% CI 0.084-0.846) to be the only independent negative predictive factor for performing LDG.

\section{Discussion}

The primary purpose of this study was to evaluate the influence of ESD on the decision regarding the type of additional gastrectomy to conduct. In this investigation, we analyzed only patients with EGC confined to the UM boundary region. Generally, the type of gastrectomy is determined by the location of the lesion. However, our results demonstrated that when considering cases limited to EGC in the UM boundary region, preoperative ESD was the only independent factor influencing the selection of gastrectomy procedure. To the best of our knowledge, this is the first report to clarify the relationship between preoperative ESD and the choice of the type of additional gastrectomy.

Our study revealed significant differences in patients' backgrounds between the surgery-only group and the ESDsurgery group. The percentages of $\mathrm{pT} 1 \mathrm{~b}$ tumor and the differentiated-type tumor were higher in the ESD-surgery group than in the surgery-only group. These results were consistent with a previous study [12]. The authors mentioned this 
Table 6 Predictive factors for LDG in patients with gastric cancer in the UM boundary region

\begin{tabular}{|c|c|c|c|c|c|c|}
\hline & \multicolumn{3}{|c|}{ Univariate analysis } & \multicolumn{3}{|c|}{ Multivariate analysis } \\
\hline & OR & $95 \% \mathrm{CI}$ & $p$ value & OR & $95 \% \mathrm{CI}$ & $p$ value \\
\hline Age (years),$<75$ vs. $\geq 75$ & 0.960 & $0.353-2.609$ & 0.936 & & & \\
\hline Sex, female vs. male & 2.589 & $0.962-6.966$ & 0.066 & 1.554 & $0.494-4.889$ & 0.451 \\
\hline BMI $\left(\mathrm{kg} / \mathrm{m}^{2}\right), \leq 23$ vs. $>23$ & 1.200 & $0.507-2.843$ & 0.679 & & & \\
\hline ASA-PS, 1 vs. 2,3 & 1.294 & $0.526-3.186$ & 0.574 & & & \\
\hline Circumference, lesser curvature vs. other & 2.178 & $0.836-5.676$ & 0.107 & & & \\
\hline Tumor size $(\mathrm{mm}), \leq 30$ vs. $>30$ & 0.500 & $0.197-1.269$ & 0.141 & & & \\
\hline $\begin{array}{l}\text { Dominant histological type, differentiated vs. undif- } \\
\text { ferentiated }\end{array}$ & 0.351 & $0.141-0.871$ & $0.022 *$ & 1.331 & $0.423-4.191$ & 0.625 \\
\hline Procedure, preoperative ESD vs. surgery only & 0.200 & $0.072-0.552$ & $0.001 *$ & 0.266 & $0.084-0.846$ & $0.025^{*}$ \\
\hline $\mathrm{pT}, \mathrm{T} 1 \mathrm{a} / 1 \mathrm{~b}$ vs $\mathrm{T} 2 / 3 / 4 \mathrm{a}$ & 0.522 & $0.131-2.085$ & 0.276 & & & \\
\hline pN, N0 vs. N1 & 0.600 & $0.147-2.441$ & 0.358 & & & \\
\hline pStage, IA/IB vs. IIA/IIB & 0.406 & $0.043-3.797$ & 0.384 & & & \\
\hline Lymphatic invasion, negative vs. positive & 0.460 & $0.117-1.810$ & 0.209 & & & \\
\hline Venous invasion, negative vs. positive & 0.564 & $0.164-1.942$ & 0.360 & & & \\
\hline
\end{tabular}

$O R$ odds ratio, $C I$ confidence interval, $B M I$ body mass index, ASA-PS American Society of Anesthesiologist physical status, ESD endoscopic submucosal dissection

${ }^{*} p<0.05$

because ESD was mainly performed among patients with absolute indications, which include the intramucosal and differentiated tumor types, while most patients diagnosed with T1a by ESD did not undergo surgery. In addition, the higher average age observed in the ESD-surgery group was similar to that observed in a previous report [12], possibly because of the biased treatment choice for older patients that would prefer minimal invasive endoscopic resection. As described, there were significant differences in patients' backgrounds; thus, we adjusted their characteristics using propensity score matching for analysis. The analysis after matching also revealed a relationship existed between ESD and type of additional gastrectomy chosen for EGC in the UM boundary region.

For EGC located in the upper third of the stomach, there are several surgical options available at this time. Conventionally, this type of case has been managed either by total or proximal gastrectomy. Patients with EGC in the upper third of the stomach usually undergo LTG or LPG, although available reports on postoperative quality of life and longterm outcomes after LTG or LPG are not as numerous as those evaluating patients post-LDG [23, 24]. In addition, laparoscopy-assisted subtotal gastrectomy (LsTG) with a very small remnant stomach, defined as LDG conducted for tumors located in the upper third of the stomach or tumors invading into the area, has been recently proposed as a procedure that can preserve the fundus [21]. Preserving the fundus maintains the secretion of ghrelin, which is mainly produced in the gastric fundic gland [25], and may better maintain the patient's nutritional status after gastrectomy.
Several studies have reported that LsTG offers a nutritionrelated advantage over other procedures for EGC in the upper third of the stomach $[15,16]$. However, future longterm observations and the further accumulation of evidence are warranted to determine the superiority of the procedure for EGC in the proximal stomach. Considering oncological safety, any of the LDG procedures including LsTG, LPG, and LTG appear to be safe for EGC in the upper third of the stomach, although the range of lymph node dissection varies with each surgical procedure [14, 26, 27]. In this study, cases of EGC located in the proximal one-half of the middle third of the stomach were also included in the analysis because the conduct of ESD in these individuals could affect the upper third of the stomach given the size of the excised mucosa at the time of ESD and subsequent scarring after ESD.

Limited information is available regarding the excised mucosa diameter for the lesion in ESD and the size of the scar in surgical specimens. In our study, the resected mucosa in ESD was a mean of $20.5 \mathrm{~mm}$ larger than the lesion diameter. In addition, the diameter of the scar in surgical specimens was a mean of $26.7 \mathrm{~mm}$ smaller than the resected specimens in ESD, which was less than one-half of the resected mucosa size. Kakushima et al. [28] investigated the healing process of gastric artificial ulcers after ESD and reported that a remarkable size reduction was observed at 4 weeks, leading to the observation of less than one-half of the initial ulcer size, which was almost the same as was noted our results. Artificial ESD ulcers have less inflammation and fibrosis of the local area than ordinary peptic ulcers [29] such that the surrounding mucosa converges due to the 
contraction of the stomach wall [30]. Because the resection of the mucosa is larger than the lesion and due to contraction of the resected area, designing a gastric resection line on the proximal side of the lesion as part of additional surgery becomes difficult. As a result, the choice of LDG could have been limited after ESD. Based on our results, the time interval between ESD and subsequent surgery did not affect the choice of surgical procedure. However, ulcer healing was affected by time; this phenomenon was likely attributable to the fact that surgery was performed on an average of 12 weeks after ESD, which was considered after complete ulcer healing. Our results suggested that LDG could have been selected if surgery was primarily performed without ESD. Although the superiority of procedures over each other is controversial, endoscopists and surgeons should recognize that the type of additional resection procedure could be affected by ESD prior to moving forward with performing ESD as a primary treatment among patients with EGC in the UM boundary region.

This study had several limitations. First, it was a retrospective single-institution study with a relatively small population. Second, various factors were involved in the decision of the procedure, and detailed indications for each gastrectomy option likely differ among facilities. Therefore, it lacked clear objective indicators for decision-making for additional gastrectomy procedures. The present study may only reflect the trend of treatment choices at a single hospital. For instance, LPG, which is more effective than LDG in dissecting lymph nodes in no. 4sb and 4sa areas, was preferred owing to the greater number of lesions observed in the greater curvature in the ESD-surgery group. Further, depending on the institution, the array of possible procedures is limited to different degrees. LPG and LsTG may not be performed without intraoperative upper gastrointestinal endoscopy or frozen section analysis. Conversely, the strength of this study is that the included patients underwent treatment with relatively uniform indication criteria and procedures because the key members involved in the surgery and treatment decisions did not change during the study period. However, this makes it difficult to generalize our results at other facilities.

In conclusion, we found that patients who underwent additional resection after ESD for EGC in the UM boundary region were more likely not to undergo LDG in comparison with those without ESD. Although the superiority of LDG or LPG/LTG is controversial, our results suggested that ESD used for EGC in the UM boundary region had an impact on the decision of procedure in the case of additional resection.

Acknowledgements The authors would like to thank Shigeo Yamaguchi, staff member at the Department of Surgery, Keio University School of Medicine, for providing assistance with the statistical analysis of data.

\section{Compliance with ethical standards}

Conflict of interest The authors declare that they have no conflict of interest.

Ethical approval All the procedures were followed in accordance with the ethical standards of the responsible committee on human experimentation (institutional and national) and with the Helsinki Declaration of 1964 and later versions.

Informed consent Informed consent or substitute for it was obtained from all patients for inclusion in the study.

\section{References}

1. Kato M, Kaise M, Yonezawa J, Toyoizumi H, Yoshimura N, Yoshida Y, et al. Magnifying endoscopy with narrow-band imaging achieves superior accuracy in the differential diagnosis of superficial gastric lesions identified with white-light endoscopy: a prospective study. Gastrointest Endosc. 2010;72:523-9.

2. Noh GY, Ku HR, Kim YJ, Park SC, Kim J, Han CJ, et al. Clinical outcomes of early gastric cancer with lymphovascular invasion or positive vertical resection margin after endoscopic submucosal dissection. Surg Endosc. 2015;29:2583-9.

3. Yamada S, Doyama H, Yao K, Uedo N, Ezoe Y, Oda I, et al. An efficient diagnostic strategy for small, depressed early gastric cancer with magnifying narrow-band imaging: a post-hoc analysis of a prospective randomized controlled trial. Gastrointest Endosc. 2014;79:55-63.

4. Japanese Gastric Cancer A. Japanese gastric cancer treatment guidelines, 2014 (ver. 4). Gastric Cancer. 2017;2017(20):1-19.

5. Gotoda T. Clinical views on the indications of endoscopic resection for mucosal gastric cancer. Gastrointest Endosc. 2016;83:902-4

6. Ono H, Yao K, Fujishiro M, Oda I, Nimura S, Yahagi N, et al. Guidelines for endoscopic submucosal dissection and endoscopic mucosal resection for early gastric cancer. Dig Endosc. 2016;28:3-15.

7. Aoyama T, Sato T, Hayashi T, Yamada T, Cho H, Ogata T, et al. Does a laparoscopic approach attenuate the body weight loss and lean body mass loss observed in open distal gastrectomy for gastric cancer? A single-institution exploratory analysis of the JCOG 0912 phase III trial. Gastric Cancer. 2018;21:345-52.

8. Kim W, Kim HH, Han SU, Kim MC, Hyung WJ, Ryu SW, et al. Decreased morbidity of laparoscopic distal gastrectomy compared with open distal gastrectomy for stage I gastric cancer: shortterm outcomes from a multicenter randomized controlled trial (KLASS-01). Ann Surg. 2016;263:28-35.

9. Kim YW, Baik YH, Yun YH, Nam BH, Kim DH, Choi IJ, et al. Improved quality of life outcomes after laparoscopy-assisted distal gastrectomy for early gastric cancer: results of a prospective randomized clinical trial. Ann Surg. 2008;248:721-7.

10. Kitano S, Shiraishi N, Uyama I, Sugihara K, Tanigawa N, Japanese Laparoscopic Surgery Study G. A multicenter study on oncologic outcome of laparoscopic gastrectomy for early cancer in Japan. Ann Surg. 2007;245:68-72.

11. Akagi T, Shiraishi N, Hiroishi K, Etoh T, Yasuda K, Kitano S. Case series of intra-abdominal adhesions induced by artificial ulceration after endoscopic submucosal dissection before additional laparoscopic gastrectomy. Gastrointest Endosc. 2010;72:438-43.

12. Lee EG, Ryu KW, Eom BW, Yoon HM, Kim YI, Cho SJ, et al. The effect of endoscopic resection on short-term surgical outcomes in 
patients with additional laparoscopic gastrectomy after non-curative resection for gastric cancer. J Gastric Cancer. 2017;17:33-42.

13. Tian YT, Ma FH, Wang GQ, Zhang YM, Dou LZ, Xie YB, et al. Additional laparoscopic gastrectomy after noncurative endoscopic submucosal dissection for early gastric cancer: a single-center experience. World J Gastroenterol. 2019;25:3996-4006.

14. Kano Y, Ohashi M, Ida S, Kumagai K, Nunobe S, Sano T, et al. Oncological feasibility of laparoscopic subtotal gastrectomy compared with laparoscopic proximal or total gastrectomy for cT1N0M0 gastric cancer in the upper gastric body. Gastric Cancer. 2019;22:1060-8.

15. Furukawa $\mathrm{H}$, Kurokawa $\mathrm{Y}$, Takiguchi $\mathrm{S}$, Tanaka K, Miyazaki $\mathrm{Y}$, Makino T, et al. Short-term outcomes and nutritional status after laparoscopic subtotal gastrectomy with a very small remnant stomach for cStage I proximal gastric carcinoma. Gastric Cancer. 2018;21:500-7.

16. Nakauchi M, Suda K, Nakamura K, Shibasaki S, Kikuchi K, Nakamura $\mathrm{T}$, et al. Laparoscopic subtotal gastrectomy for advanced gastric cancer: technical aspects and surgical, nutritional and oncological outcomes. Surg Endosc. 2017;31:4631-40.

17. Hiki N, Katai H, Mizusawa J, Nakamura K, Nakamori M, Yoshikawa $\mathrm{T}$, et al. Long-term outcomes of laparoscopy-assisted distal gastrectomy with suprapancreatic nodal dissection for clinical stage I gastric cancer: a multicenter phase II trial (JCOG0703). Gastric Cancer. 2018;21:155-61.

18. Katai H, Mizusawa J, Katayama H, Takagi M, Yoshikawa T, Fukagawa T, et al. Short-term surgical outcomes from a phase III study of laparoscopy-assisted versus open distal gastrectomy with nodal dissection for clinical stage IA/IB gastric cancer: Japan Clinical Oncology Group Study JCOG0912. Gastric Cancer. 2017;20:699-708.

19. Katai H, Sasako M, Fukuda H, Nakamura K, Hiki N, Saka M, et al. Safety and feasibility of laparoscopy-assisted distal gastrectomy with suprapancreatic nodal dissection for clinical stage I gastric cancer: a multicenter phase II trial (JCOG 0703). Gastric Cancer. 2010;13:238-44.

20. Katai H, Mizusawa J, Katayama H, Kunisaki C, Sakuramoto $\mathrm{S}$, Inaki N, et al. Single-arm confirmatory trial of laparoscopyassisted total or proximal gastrectomy with nodal dissection for clinical stage I gastric cancer: Japan Clinical Oncology Group study JCOG1401. Gastric Cancer. 2019;22:999-1008.

21. Jiang X, Hiki N, Nunobe S, Nohara K, Kumagai K, Sano T, et al. Laparoscopy-assisted subtotal gastrectomy with very small remnant stomach: a novel surgical procedure for selected early gastric cancer in the upper stomach. Gastric Cancer. 2011;14:194-9.

22. Kawata N, Kakushima N, Tokunaga M, Tanaka M, Sawai H, Takizawa $\mathrm{K}$, et al. Influence of endoscopic submucosal dissection on additional gastric resections. Gastric Cancer. 2015;18:339-45.

23. Ahn SH, Lee JH, Park DJ, Kim HH. Comparative study of clinical outcomes between laparoscopy-assisted proximal gastrectomy (LAPG) and laparoscopy-assisted total gastrectomy (LATG) for proximal gastric cancer. Gastric Cancer. 2013;16:282-9.

24. Lee SE, Ryu KW, Nam BH, Lee JH, Kim YW, Yu JS, et al. Technical feasibility and safety of laparoscopy-assisted total gastrectomy in gastric cancer: a comparative study with laparoscopyassisted distal gastrectomy. J Surg Oncol. 2009;100:392-5.

25. Takiguchi S, Adachi S, Yamamoto K, Morii E, Miyata H, Nakajima K, et al. Mapping analysis of ghrelin producing cells in the human stomach associated with chronic gastritis and early cancers. Dig Dis Sci. 2012;57:1238-46.

26. Etoh T, Honda M, Kumamaru H, Miyata H, Yoshida K, Kodera Y, et al. Morbidity and mortality from a propensity score-matched, prospective cohort study of laparoscopic versus open total gastrectomy for gastric cancer: data from a nationwide web-based database. Surg Endosc. 2018;32:2766-73.

27. Hosoda K, Yamashita K, Katada N, Moriya H, Mieno H, Shibata $\mathrm{T}$, et al. Potential benefits of laparoscopy-assisted proximal gastrectomy with esophagogastrostomy for cT1 upper-third gastric cancer. Surg Endosc. 2016;30:3426-36.

28. Kakushima N, Yahagi N, Fujishiro M, Iguchi M, Oka M, Komayashi $\mathrm{K}$, et al. The healing process of gastric artificial ulcers after endoscopic submucosal dissection. Dig Endosc. 2004;16:327-31.

29. Hashimoto T, Adachi K. Changes in gastric mucosal blood flow during healing of EMR-induced ulcer-comparison with peptic ulcer. Dig Endosc. 1997;9:127-31.

30. Kakushima N, Fujishiro M, Kodashima S, Kobayashi K, Tateishi A, Iguchi M, et al. Histopathologic characteristics of gastric ulcers created by endoscopic submucosal dissection. Endoscopy. 2006;38:412-5.

Publisher's Note Springer Nature remains neutral with regard to jurisdictional claims in published maps and institutional affiliations. 